\title{
Advanced dental reduction in Javanese Homo erectus
}

\author{
YOUSUKE KAIFU ${ }^{1 *}$ \\ ${ }^{1}$ Department of Anthropology, National Science Museum, 3-23-1 Hyakunin-cho, Shinjuku-ku, Tokyo, 169-0073 Japan
}

Received 29 July 2004; accepted 8 June 2005

\begin{abstract}
The postcanine tooth crowns of late Early Pleistocene Homo erectus from Sangiran, Java, have been considered to be significantly smaller than those of older $H$. erectus remains of the same region. In this study, the degree of dental reduction in the former was examined by comparing their postcanine crown size with that of various regional groups of recent $H$. sapiens. The results show that overall crown size and degree of posterior molar reduction of Javanese H. erectus of the late Early Pleistocene was within the range of variation of recent $H$. sapiens. The position of this $H$. erectus group in the general trend of dental reduction in Early to Middle Pleistocene Asian archaic Homo is discussed. Implications for the phylogenetic discontinuity hypothesis between $H$. erectus and H. sapiens in Australasia are presented. In contrast to their reduced crown size, the Javanese $H$. erectus remains exhibit robust root systems, presumably a primitive retention. This observation indicates that reduction in crown size preceded reduction of the roots during evolution of Homo, at least in the Sunda region.
\end{abstract}

Key words: dental reduction, Homo erectus, Sangiran, tooth size, root morphology

\section{Introduction}

Crown size reduction in the posterior teeth is a general trend observed in the evolution of the genus Homo for over two million years (Bermúdez de Castro and Nicolas, 1995, and references therein). The earliest form of Homo from the Pliocene of Africa had, on average, larger posterior teeth than seen in $H$. erectus from the Pleistocene of Africa and Eurasia. Tooth size is further reduced in later archaic Homo such as Neanderthals, and in H. sapiens. Dental reduction seems to have occurred also within the species $H$. erectus, although there probably was regional variation in its rate. For example, the dental remains of the Middle Pleistocene $H$. erectus from Zhoukoudian, northern China, are known to show size reduction particularly in their posterior molars compared to earlier H. erectus from Africa (Wolpoff, 1980; Bräuer and Schultz, 1996; Kaifu et al., 2005b).

A recent study of the Early Pleistocene mandibles and teeth of $H$. erectus from Sangiran, Central Java, indicated substantial morphological differences between the chronologically older (earlier Early Pleistocene) and younger (late Early Pleistocene) assemblages (Kaifu et al., 2003, 2005b). While the chronologically older mandibles and teeth from Sangiran show some features that are equally or even more primitive than early $H$. erectus (or $H$. ergaster) of Africa, the chronologically younger specimens are morphologically advanced, showing a marked degree of dentognathic reduc-

Collected Papers in Honor of Professor Emeritus Banri Endo: Commemoration of His Seventieth Birthday

* Corresponding author. e-mail: kaifu@kahaku.go.jp phone: +81-3-3364-7140; fax: +81-3-3364-7104

Published online 13 September 2005

in J-STAGE (www.jstage.jst.go.jp) DOI: 10.1537/ase.040729 tion. This latter tendency includes crown size reduction in the postcanine teeth, which is comparable to that in Zhoukoudian H. erectus, as was suggested by Thorne and Wolpoff (1981).

Because cranial evidence is not sufficiently known or analyzed at the present state of research, it still remains unclear whether the chronological changes observed in the Sangiran dentognathic specimens are ascribed to significant in situ evolution or replacement of populations in the Sunda region (Kaifu et al., 2005b). However, the advanced crown size reduction of the late Early Pleistocene $H$. erectus of Java compared to their African contemporaries is intriguing. In particular, its relevance to elucidating regional trends of dental reduction and phylogenetic relationships between $H$. erectus and $H$. sapiens in the Sunda region is worth pursuing. The purpose of this study is to further explore and evaluate the degree of dental reduction seen in the late Early Pleistocene $H$. erectus from Sangiran, by comparing their tooth crown size with various regional groups of $H$. sapiens.

\section{Materials and Methods}

Three major stratigraphic units are identified in the hominid fossil bearing sequences in the Sangiran region. They are, from the lower to the upper, the uppermost part of the Sangiran (Pucangan) Formation, the Grenzbank zone at the base of the Bapang (Kabuh) Formation, and the middle to lower parts of the Bapang Formation. The dental remains of Javanese $H$. erectus examined in this study are those from the upper part of the sequence, namely, the Bapang Formation above the Grenzbank zone. Currently, there are two conflicting views on the absolute dates of this stratigraphic level. While a younger chronology (Hyodo et al., 1993, 2002) suggests ca. 1.0-0.8 Ma, an older chronology (Larick 
et al., 2001) proposes ca. 1.5-1.0 Ma. In spite of the potentially great age range (up to 200 or $500 \mathrm{kyr}$ ), the $H$. erectus cranial, mandibular, and dental remains of the Bapang Formation above the Grenzbank zone share similar morphological characteristics (Thorne and Wolpoff, 1981; Arif et al., 2002; Kaifu et al., 2005b); there is no reason at present to suspect the existence of more than one population within this sample.

Table 1 lists the Sangiran $H$. erectus specimens used in this study. The original stratigraphic levels of the dentitions from five jaw specimens are known or reliably inferred. In addition to these, a part of the Sangiran 7 isolated dental specimens collected by Koenigswald during 1936-1941 is included. Koenigswald's stratigraphic allocation for the Sangiran 7 specimens was given in Grine and Franzen (1994), but the reliability of this information is open to question according to these authors. Fossils from the Bapang Formation, Grenzbank zone, and Sangiran Formation can usually be distinguished by their state of fossilization, although inferences based on fragmentary material such as isolated teeth need particular caution. I examined the original fossil materials of Sangiran 7 with Fachroel Aziz and Hisao Baba. We concluded that Koenigswald's allocation as 'Kabuh Formation' for the 13 specimens listed in Table 1 seemed likely to be correct, with the exception of one maxillary first molar specimen, Sangiran 7-8. However, the crown size of this specimen is almost identical to the mean size of the other maxillary first molars listed in Table 1, and inclusion or exclusion of this specimen does not affect the results of this study.

The crown size and the proportion of the postcanine teeth of the chronologically younger Sangiran $H$. erectus were compared with those of recent or contemporary H. sapiens from various regions of the world. These comparative samples were selected from published data compiled by Mizoguchi (1988) and Kieser (1990). Mizoguchi (1988,

Table 1. Homo erectus materials from Sangiran used in this study

\begin{tabular}{lll}
\hline Specimen & Description $^{\text {a }}$ & References \\
\hline Sangiran 17 & Maxillary left P2-M3 & Arif et al. (2002) \\
Sangiran 21 & Mandibular right M3 & Kaifu et al. (2005a) \\
Skull IX & Maxillary right M1-M3 & Arif et al. (2002) \\
Sb 8103 & Mandibular right P2-M3 & Kaifu et al. (2005a) \\
Ng 8503 & Mandibular right M1-M2 Kaifu et al. (2005a) \\
Sangiran 7-3 & Maxillary right P2-M3 & Grine and Franzen (1994) \\
Sangiran 7-8 & Maxillary left M1 & Grine and Franzen (1994) \\
Sangiran 7-9 & Maxillary right M2 & Grine and Franzen (1994) \\
Sangiran 7-10 & Maxillary right M1 & Grine and Franzen (1994) \\
Sangiran 7-17 & Maxillary right M3 & Grine and Franzen (1994) \\
Sangiran 7-20 & Mandibular left M2 & Grine and Franzen (1994) \\
Sangiran 7-25 & Mandibular right P1 & Grine and Franzen (1994) \\
Sangiran 7-26 & Mandibular right P2 & Grine and Franzen (1994) \\
Sangiran 7-27 & Maxillary left P1 & Grine and Franzen (1994) \\
Sangiran 7-29 & Maxillary right P2 & Grine and Franzen (1994) \\
Sangiran 7-30 & Maxillary right P2 & Grine and Franzen (1994) \\
Sangiran 7-31 & Maxillary left P1 & Grine and Franzen (1994) \\
Sangiran 7-32 & Maxillary right P1 & Grine and Franzen (1994) \\
\hline a Tooth position was identified by Y.K. based on the original speci- \\
mens.
\end{tabular}

1993), using mesiodistal and buccolingual diameters of all teeth except the third molar, investigated variability of tooth size and shape among modern human populations from all over the world. He recognized several representative morphological variations in these worldwide populations. In the present study, comparative modern human samples were selected so that they represent these major variations of the modern world. Emphasis was laid on populations with larger teeth (Australian Aborigines and Inuit), because crown size of the Sangiran $H$. erectus sample falls around the upper limit of the entire variation of modern humans (see below). Other criteria for sample selection included moderate sample size and availability of data for the third molar.

The anterior teeth were excluded from the analyses because of small sample sizes in Sangiran H. erectus. The square root of computed crown area, which is the product of mesiodistal (MD) and buccolingual (BL) crown diameters, was used as the parameter representing tooth crown size. Measurements of the Sangiran H. erectus sample were taken by the author, following the methods of Wood (1991). This method corrects for interproximal wear and records an estimated MD dimension of the unworn condition. Because a part of the comparative data of $H$. sapiens may be based on worn teeth without correction for interproximal wear, uncorrected original MD dimensions of the Sangiran specimens were also taken from contact point to contact point and used to calculate a second set of crown size variables. The ratio of crown size of the first and second molars, and that of the first and third molars were calculated in order to compare the degree of posterior molar reduction.

Potentially important factors that might affect the results of this study are inter-observer differences in measurement method, effects of tooth wear on dental dimensions, and potential biases in sex ratio of the fossil samples. Such issues are discussed below.

\section{Results}

The left side of Table 2 shows tooth size and molar size proportion of five Sangiran $H$. erectus specimens with associated tooth rows. The mean values of tooth size and molar size proportion of the $H$. erectus sample are shown on the right side of Table 2, either for samples excluding (Sangiran set A) or including (Sangiran set B) the Sangiran 7 specimens whose stratigraphic information is more or less uncertain. Values based on the MD dimensions uncorrected for interproximal wear are indicated in parentheses. Overall, the differences between corrected and uncorrected figures are slight when compared to the variation seen among recent $H$. sapiens populations (Table 3 ).

The mean values of Sangiran sets A and B are generally close or identical. Table 2 also shows that within-group variation in tooth size and molar size proportions of the combined Sangiran sample (Sangiran set B) are relatively small when compared to the between-group variation seen among recent $H$. sapiens (discussed below). This suggests that the present Sangiran $H$. erectus sample adequately represents its population in spite of the small sample size.

Table 3 shows mean tooth size and molar proportion of the various recent or contemporary $H$. sapiens populations from 
Table 2. Crown size of the postcanine teeth and molar size proportion in the late Early Pleistocene Homo erectus from Sangiran ${ }^{\mathrm{a}, \mathrm{b}}$

\begin{tabular}{|c|c|c|c|c|c|c|c|c|c|c|c|c|c|c|}
\hline \multirow[b]{3}{*}{ Maxilla } & \multirow[b]{3}{*}{ P1 } & \multirow[t]{2}{*}{ Sangiran 7-3 } & \multirow[t]{3}{*}{ Sangiran 17} & \multirow[t]{2}{*}{ Skull IX } & \multirow[t]{2}{*}{$\mathrm{Sb} 8103$} & \multirow[t]{3}{*}{ Ng 8503} & \multicolumn{3}{|c|}{ Sangiran set $\mathrm{A}^{\mathrm{c}}$} & \multicolumn{5}{|c|}{ Sangiran set $\mathrm{B}^{\mathrm{d}}$} \\
\hline & & & & & & & \multirow[t]{2}{*}{$n$} & \multicolumn{2}{|c|}{ Mean } & \multirow[t]{2}{*}{$n$} & \multicolumn{2}{|c|}{ Mean } & \multicolumn{2}{|c|}{ Range } \\
\hline & & & & & & & & - & - & & 9.1 & $(9.0)$ & $9.0-9.2$ & $(8.8-9.2)$ \\
\hline & P2 & $8.6 \quad(8.3)$ & $9.0 \quad(8.9)$ & & & & 1 & 9.0 & $(8.9)$ & 4 & 8.9 & (8.7) & 8.6-9.1 & $(8.3-9.0)$ \\
\hline & M1 & 12.0 & 12.1 & 12.1 & & & 2 & 12.1 & (11.8) & 5 & 12.0 & (11.7) & $11.7-12.1$ & $(11.6-11.8)$ \\
\hline & M2 & $12.0(11.8)$ & $11.9(11.8)$ & $12.2(11.9)$ & & & 2 & 12.1 & (11.8) & 4 & 12.2 & $(12.0)$ & $11.9-12.6$ & (11.8-12.3) \\
\hline & M3 & $10.6(10.6)$ & $11.2(11.1)$ & 11.0 & & & 2 & 11.1 & (11.1) & 4 & 10.9 & $(10.8)$ & $10.6-11.2$ & $(10.4-11.1)$ \\
\hline & $(\mathrm{M} 2 / \mathrm{M} 1) \times 100^{\mathrm{e}}$ & 100 & $98(100)$ & 101 & & & & 100 & $(100)$ & & 101 & (103) & 98-101 & $(100-101)$ \\
\hline & $(\mathrm{M} 3 / \mathrm{M} 1) \times 100^{\mathrm{e}}$ & $88 \quad(90)$ & $93 \quad(94)$ & $91 \quad(93)$ & & & & 92 & (94) & & 90 & $(92)$ & $88-93$ & $(90-94)$ \\
\hline \multirow[t]{7}{*}{ Mandible } & P1 & & & & & & 0 & - & - & 1 & 8.4 & $(8.3)$ & 8.4 & (8.3) \\
\hline & $\mathrm{P} 2$ & & & & $9.4 \quad(9.3)$ & & 1 & 9.4 & $(9.3)$ & 2 & 8.8 & (8.7) & $8.2-9.4$ & $(8.2-9.3)$ \\
\hline & M1 & & & & $12.2(11.8)$ & $12.1(12.0)$ & 2 & 12.2 & (11.9) & 2 & 12.2 & (11.9) & $12.1-12.2$ & $(11.8-12.0)$ \\
\hline & M2 & & & & $12.5(12.2)$ & $13.0(13.0)$ & 2 & 12.8 & (12.6) & 3 & 12.5 & (12.3) & $11.9-13.0$ & $(11.7-13.0)$ \\
\hline & M3 & & & & $11.6(11.4)$ & & 2 & 11.6 & (11.5) & 2 & 11.6 & (11.5) & 11.6 & (11.4-11.5) \\
\hline & $(\mathrm{M} 2 / \mathrm{M} 1) \times 100^{\mathrm{e}}$ & & & & 102 & 107 & & 105 & (106) & & 103 & (103) & 102-107 & $(103-108)$ \\
\hline & $(\mathrm{M} 3 / \mathrm{M} 1) \times 100^{\mathrm{e}}$ & & & & $95 \quad(96)$ & & & 95 & (97) & & 95 & (97) & 95 & (96) \\
\hline
\end{tabular}

${ }^{\mathrm{a}}$ Tooth crown size is the square root of computed crown area.

${ }^{\mathrm{b}}$ Figures based on the MD dimensions uncorrected for interproximal wear are in parentheses.

${ }^{\mathrm{c}}$ Sangiran Homo erectus sample excluding Sangiran 7.

${ }^{\mathrm{d}}$ Sangiran Homo erectus sample including Sangiran 7.

${ }^{\mathrm{e}}$ The means for Sangiran sets A and B are calculated from the mean for each molar.

the Arctic region, Eurasia, Australia, and Africa. These samples include populations with large, medium, and small tooth crowns. In general postcanine tooth size, Sangiran $H$. erectus is close to recent Australian Aborigines of the precontact or contact periods (Broadbeach, Swanport, Western Australia), whose teeth are the largest among recent $H$. sapiens populations.

Second molar size relative to first molar size is similar between the maxillary and mandibular dentitions in all the modern human samples. In all the $H$. sapiens samples except the Tibetan male, the third molar is reduced relative to the first molar more so in the maxillary than in the mandibular dentition. These general tendencies seen among modern humans apply to Sangiran H. erectus.

Among the $H$. sapiens samples, the sample with the smallest postcanine teeth (Tibetan) tends to show extremely advanced size reduction of the posterior molars. On the contrary, second molar size tends to be equal to or exceed first molar size in southeastern and western Australian Aborigines who have large teeth (Broadbeach, Swanport, and Western Australia). The mean relative second molar size of Sangiran $H$. erectus is equal to those of male Aborigines from Broadbeach and female Aborigines from western Australia.

Maxillary third molar size relative to first molar size is equal to or above $90 \%$ in all the Australian Aborigine samples, while modern human populations from other regions commonly have an index under $90 \%$. The mean value of Sangiran $H$. erectus is $90 \%$, which is close to the average condition for the entire series of $H$. sapiens populations, although the mean based on figures uncorrected for interproximal wear approaches the Australian Aborigine condition.

Relative mandibular third molar size is over $95 \%$ in many H. sapiens samples. The third molars of some Australian and African samples are on average actually equal to or even larger than the first molars. The small sample of Sangiran $H$. erectus shows a moderate degree of third molar reduction relative to the first molars.

\section{Discussion}

In spite of the small sample size and potentially great age range (200 or $500 \mathrm{kyr}$ ), the limited degree of variation observed in the present $H$. erectus sample suggests that this sample adequately represents the posterior tooth crown size of the Javanese $H$. erectus population of the late Early Pleistocene. The present $H$. erectus sample includes both supposedly male (Sangiran 17) and supposedly female (Skull IX) individuals (Arif et al., 2002). Because tooth size was approximately equivalent between these two individuals, the mean values obtained from the present sample are unlikely to be affected by any potential bias in sex ratio.

The above comparisons suggest that this $H$. erectus population was at the margin of the range of variation of modern humans in postcanine tooth size and relative second molar size. The late Early Pleistocene $H$. erectus from Java is similar in these characteristics to recent Australian Aborigines of the pre-contact or contact periods, whose teeth are the largest among recent $H$. sapiens populations. Aboriginal populations in southeastern Australia around the Pleistocene-Holocene boundary had even larger teeth than the Holocene populations compared here, particularly in males (Brown, 1989, 1992a).

Relative third molar size of Sangiran $H$. erectus is also within the range of variation of modern humans. The observed degree of reduction of this tooth is close to the average condition seen among recent $H$. sapiens populations from various regions of the world. In fact, third molar reduction in late Early Pleistocene H. erectus from Java seems to be slightly advanced compared to that in Australian Aborigines. Although the $H$. erectus sample size is still limited, this observed tendency is consistently seen in both maxillary and mandibular dentitions.

Two important potential factors that might affect the above interpretations are inter-observer differences in mea- 


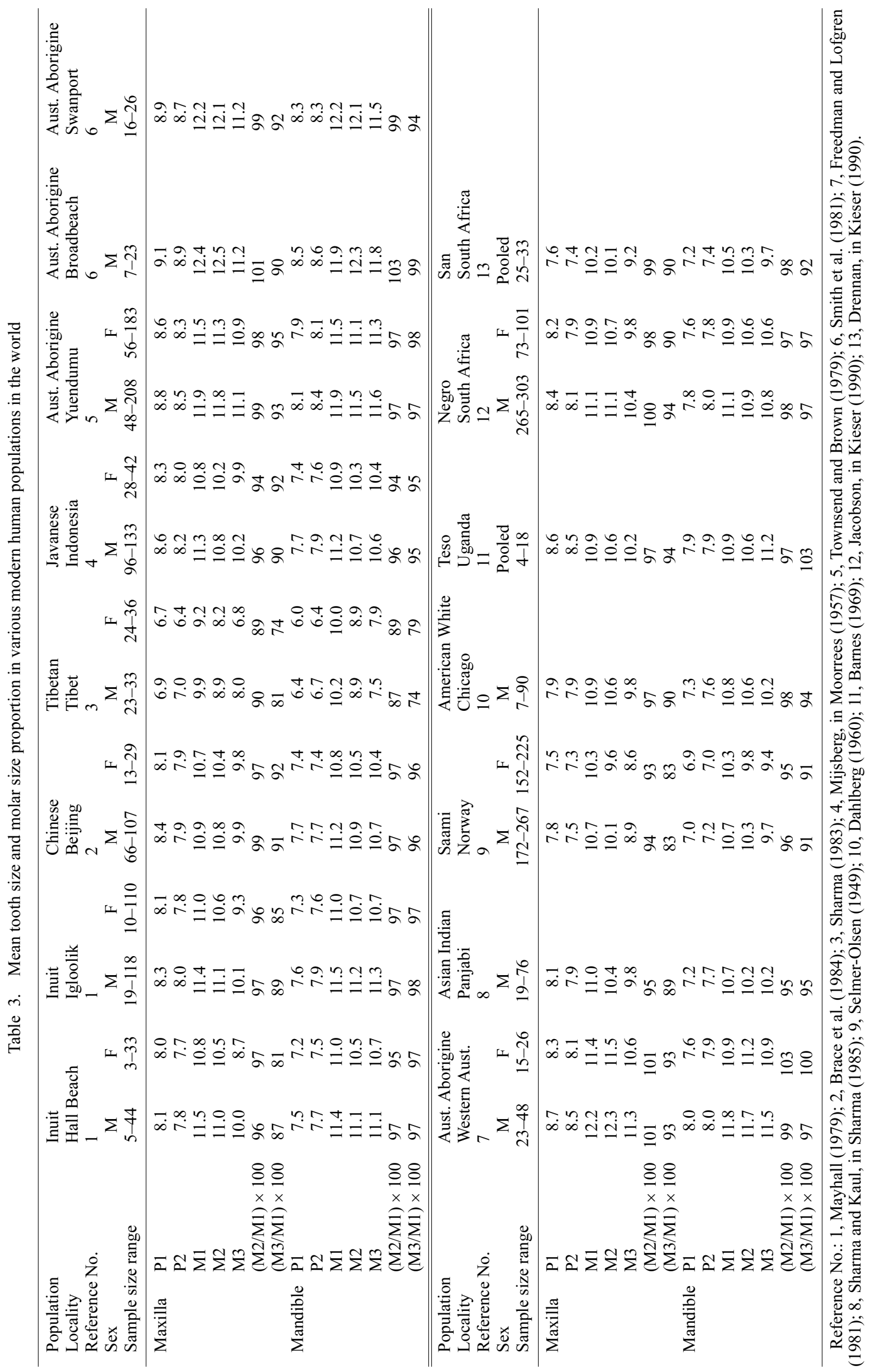


surement method and the effects of tooth wear. Actual details of the measurement methods adopted in the various studies cited in Table 3 are unclear in many cases. In addition, it is impossible to evaluate from the literature the actual effects of wear in these samples, although many of the comparative $H$. sapiens samples are unlikely to have suffered severe wear compared to their prehistoric ancestors. However, the tooth crowns of the present Sangiran H. erectus sample were measured using the method of Wood (1991), which tends to produce greater MD measurements. In this method, the MD dimension of a maxillary molar is defined as the "distance between the two parallel lines, perpendicular to the longitudinal axis of the tooth, which are tangential of the most mesial and distal points, respectively." The MD dimension of a mandibular molar is defined as the "maximum distance between the mesial and distal crown borders, taken parallel with the longitudinal axis of the crown." Furthermore, in this method, the MD dimensions were corrected for interproximal wear. Thus, the conclusion that the present $H$. erectus sample is within the range of variation of modern humans in postcanine tooth size is not affected by these two factors.

The above results regarding molar size proportions are less definite in this respect, but the influence of the two factors on tooth size ratios is probably limited because each comparative sample was measured by the same researcher(s). In order to examine the influence of the two factors in the Sangiran $H$. erectus sample, figures based on the two different measurement methods were examined (Table 2). The observed differences between the two sets of reduction indices are slight and do not affect the above interpretations.

The above findings suggest that $H$. erectus in Java had already experienced a considerable degree of crown size reduction by about one million years ago, and had entered the range of variation of modern $H$. sapiens. However, at present, few hominid remains are known from the Early Pleistocene of mainland Asia, and it is unclear when and how this level of crown size reduction occurred in this region. The Sangiran hominid remains found just below the stratigraphic levels of the late Early Pleistocene sample examined here (those from the uppermost part of the Sangiran Formation and Grenzbank zone in Sangiran) have premolars and molars about $10 \%$ larger than the latter (Kaifu, $2005 \mathrm{~b}$, unpublished data). They also show a smaller degree of posterior molar reduction. But at present, the phylogenetic relationship between these two chronological populations of Sangiran is not clear because of the paucity of information available on cranial morphology, and because the causative background of advanced dental reduction seen in the chronologically younger Sangiran $H$. erectus is not yet known.

A similar degree of crown size reduction is documented in the Middle Pleistocene $H$. erectus remains from Zhoukoudian, northern China (Weidenreich, 1937; Wolpoff, 1980; Bräuer and Schultz, 1996; Kaifu et al., 2005b), and the teeth associated with a mandible from the early Middle Pleistocene site at Lantian, China, also show size reduction (Woo, 1964; Kaifu et al., 2005b). However, the Middle Pleistocene site of Hexian, eastern China, yielded several teeth that were larger than the Zhoukoudian specimens (Wu and Dong, 1982; Wu, 1983; Wu and Poirier, 1995; P. Brown, personal communication). Therefore, there remains a possibility that dental reduction observed in northern China and Java occurred independently in the two regions. Evidence from the earlier periods of Eurasia is more limited, but the dental remains from Dmanisi nevertheless suggest that postcanine tooth size was highly variable at the Plio-Pleistocene boundary in the Caucasus (Gabunia et al., 2002; Kaifu et al., 2005b).

Apart from the above unanswered questions regarding the processes leading to the observed reduction, the marked degree of crown size reduction documented here for late Early Pleistocene $H$. erectus of Java is suggestive in terms of elucidating modern human origins in Australasia (Brown, 1992b; Hawks et al., 2000; Baba et al., 2003). Recent studies of cranial morphology strongly suggest that Javanese $H$. erectus during and after the late Early Pleistocene formed a continuously evolving population lineage that was effectively independent of the $H$. erectus populations of northern China (Antón, 2002; Baba et al., 2003; Durband et al., 2005). If crown size reduction was a continuing trend in later Javanese $H$. erectus during the Middle/Late Pleistocene, like in those cases recognized in various regional groups of archaic Homo in Africa, Europe, and China (Zhang, 1991; Bermúdez de Castro and Nicolas, 1995; Bräuer and Schúltz, 1996; Kaifu et al., 2005b), it is likely that Javanese H. erectus was not ancestral to Australian Aborigines. This is because their posterior teeth, at about one million years ago, were already reduced to the degree comparable to that found in some recent Australian Aborigines (cf. Thorne and Wolpoff, 1981). Early H. sapiens, such as represented by the Qafzeh hominids of West Asia, also had relatively big teeth (Table 4), and there is no contradiction if the first Australians inherited these dental characters from early Late Pleistocene $H$. sapiens from the west. This suggestion of possible discontinuity between $H$. erectus and $H$. sapiens in the Sunda region agrees with inferences drawn from the cranial evidence (Baba et al., 2003; Durband, 2004), and differs from the suggestion made by Kramer (1991) based on dental traits of the earlier Early Pleistocene hominids from Sangiran.

However, in contrast to the relatively abundant cranial remains, there are very few dental remains of archaic hominids from the Middle/Late Pleistocene deposits of the Sunda region. Therefore, the actual trend of dental evolution in the Javanese $H$. erectus lineage during this period cannot be assessed at present. The recently discovered skeleton of $H$. floresiensis, a possible dwarf descendant of $H$. erectus in the terminal Late Pleistocene of Flores Island, has tooth crowns that are similar in absolute buccolingual dimensions to $H$. sapiens (Brown et al., 2004). However, this is probably a unique case in an isolated island environment, and cannot be a good guide to infer the past situation in the Sunda region. Also, the dental characteristics of the first Australians at about $40-50 \mathrm{ka}$ are not known. Thus, it is also possible that the megadont condition of recent Australians was a later adaptation after their migration to the Sahul, although such a positive evolutionary change in tooth size, if it occurred, would have been an exceptional case for $H$. sapiens in the prehistoric period. 
Table 4. Crown size and molar size proportion in H. sapiens from Qafzeh ${ }^{\mathrm{a}}$

\begin{tabular}{|c|c|c|c|c|c|c|c|}
\hline & & Qafzeh 5 & Qafzeh 6 & Qafzeh 7 & Qafzeh 8 & Qafzeh 9 & Mean \\
\hline \multirow[t]{7}{*}{ Maxilla } & $\mathrm{P} 1$ & 8.7 & 8.4 & 9.0 & 8.5 & 9.6 & 8.8 \\
\hline & $\mathrm{P} 2$ & 7.9 & 8.1 & 8.6 & 8.2 & 9.1 & 8.4 \\
\hline & M1 & 11.2 & 11.8 & 12.0 & 12.2 & 12.5 & 11.9 \\
\hline & M2 & & 11.7 & 11.5 & & 12.0 & 11.7 \\
\hline & M3 & & & 10.7 & & 11.4 & 11.1 \\
\hline & $(\mathrm{M} 2 / \mathrm{M} 1) \times 100$ & & 99 & 96 & & 96 & 97 \\
\hline & $(\mathrm{M} 3 / \mathrm{M} 1) \times 100$ & & & 89 & & 91 & 90 \\
\hline \multirow[t]{7}{*}{ Mandible } & $\mathrm{P} 1$ & & & 8.3 & 7.9 & 9.0 & 8.4 \\
\hline & $\mathrm{P} 2$ & & & 8.5 & 7.4 & 9.1 & 8.3 \\
\hline & M1 & & & 11.5 & 12.1 & 12.7 & 12.1 \\
\hline & M2 & & & 11.2 & 11.2 & 12.1 & 11.5 \\
\hline & M3 & & & 11.6 & 11.9 & 12.3 & 11.9 \\
\hline & $(\mathrm{M} 2 / \mathrm{M} 1) \times 100$ & & & 97 & 93 & 95 & 95 \\
\hline & $(\mathrm{M} 3 / \mathrm{M} 1) \times 100$ & & & 101 & 98 & 97 & 99 \\
\hline
\end{tabular}

${ }^{\text {a }}$ Tooth crown size is the square root of computed crown area. Data are from Vandermeersch (1981).

Root size and morphology of Javanese H. erectus have not been studied comprehensively, but some important information is available from the existing publications. Weidenreich (1937) reported that the tooth roots of Zhoukoudian $H$. erectus were more robust than those of modern humans. This applies to the late Early Pleistocene H. erectus from Java investigated here.

Kaifu et al. $(2005 b, c)$ suggested that the premolar root is more reduced in the chronologically younger than older $H$. erectus assemblages from Sangiran. While the older assemblage shows moderate frequencies of three-rooted maxillary and two-rooted mandibular premolars, the specimens from the upper stratigraphic levels show a two-rooted maxillary premolar (Sangiran 17) and a mandibular premolar with its conical buccal and lingual components fused extensively ( $\mathrm{Sb} 8103$ ). However, the premolar roots of the chronologically younger Sangiran $H$. erectus are not so reduced as those of modern humans, and still retain primitive morphology shared with other Early/Middle Pleistocene archaic Homo.

The buccal and lingual components of the maxillary premolar and molar roots of Sangiran 17 are heavily built, and well separated from each other (Figure 1, Figure 2; Kaifu et al., 2005c). This contrasts with the condition typically seen among modern humans, in which these components are only moderately separated from each other or fused. The mandibular second premolar root of Sb 8103 is long (the buccal root height is $16 \mathrm{~mm}$ ) and buccolingually broad, with maximum buccolingual breadth situated at around mid-level of root height. Both the buccal and lingual components of the root are bulbous, and unlike the slender and pointed roots of modern human second premolars. Lateral radiographs show that the mandibular molars of Sangiran 21, Sb 8103, and Ng 8503 all show mesial and distal roots that are thick throughout their length (Kaifu et al., 2005a). These tendencies of thick and divergent roots are apparently shared with many other archaic hominids including Zhoukoudian $H$. erectus (e.g. Weidenreich, 1937; Wood et al., 1988), although a numerical comparison based on a larger sample is needed to further clarify the details regarding morphological variation of the root system in fossil and modern hominids.
Thus, the reduced dentition of late Early Pleistocene Javanese $H$. erectus had its own characteristics which were different from those of recent $H$. sapiens. While this $H$. erectus population was similar to some recent $H$. sapiens populations in terms of the size of the postcanine tooth crowns, their roots were disproportionally robust and divergent when compared to modern human standards.

The disparity of crown-root proportions between late Early Pleistocene $H$. erectus and modern $H$. sapiens probably reflects differential functional demands on the crown and root. The primary factor influencing crown size seems to be the nature of the foods consumed (ease of fracture, toughness, abrasiveness, amount, etc.) (e.g. Mizoguchi, 1993), but other diverse factors such as power and direction of the jaw movement, surface morphology of tooth crowns, and longevity may also be related to this characteristic. On the other hand, mechanical demand is likely to be the most influential factor that affects morphology of the tooth roots. The thick and divergent roots of Sangiran $H$. erectus (and many other archaic hominids) are best explained as an adaptation to a habitually strong bite force both vertically and horizontally. The cranial morphology of Sangiran H. erectus (and other archaic hominids) seems to be consistent with this expectation. The development of some ectocranial superstructures in Sangiran 17, such as the suprameatal and supramastoid crests, strong postorbital constriction and deep temporal gutter, and massive zygomatic arch (preserved elements are the zygomatic root of the temporal and the posteroinferior border of the zygomatic), and other Sangiran crania at least suggest that their temporal and masseter muscles were thicker and more voluminous than the modern human condition. In modern humans, mediolateral movement of the mandible is led mainly by the masseter muscle and the deep portion of the temporal muscle (Kasai and Iida, 2001). Therefore, bite force applied on the teeth of these $H$. erectus was probably significantly stronger both vertically and horizontally than in the case of modern humans.

In sum, there exist two related but different aspects of hominid 'dental reduction': reduction of the crown and reduction of the root system. The observations of this study suggest that the former preceded the latter in the evolution- 


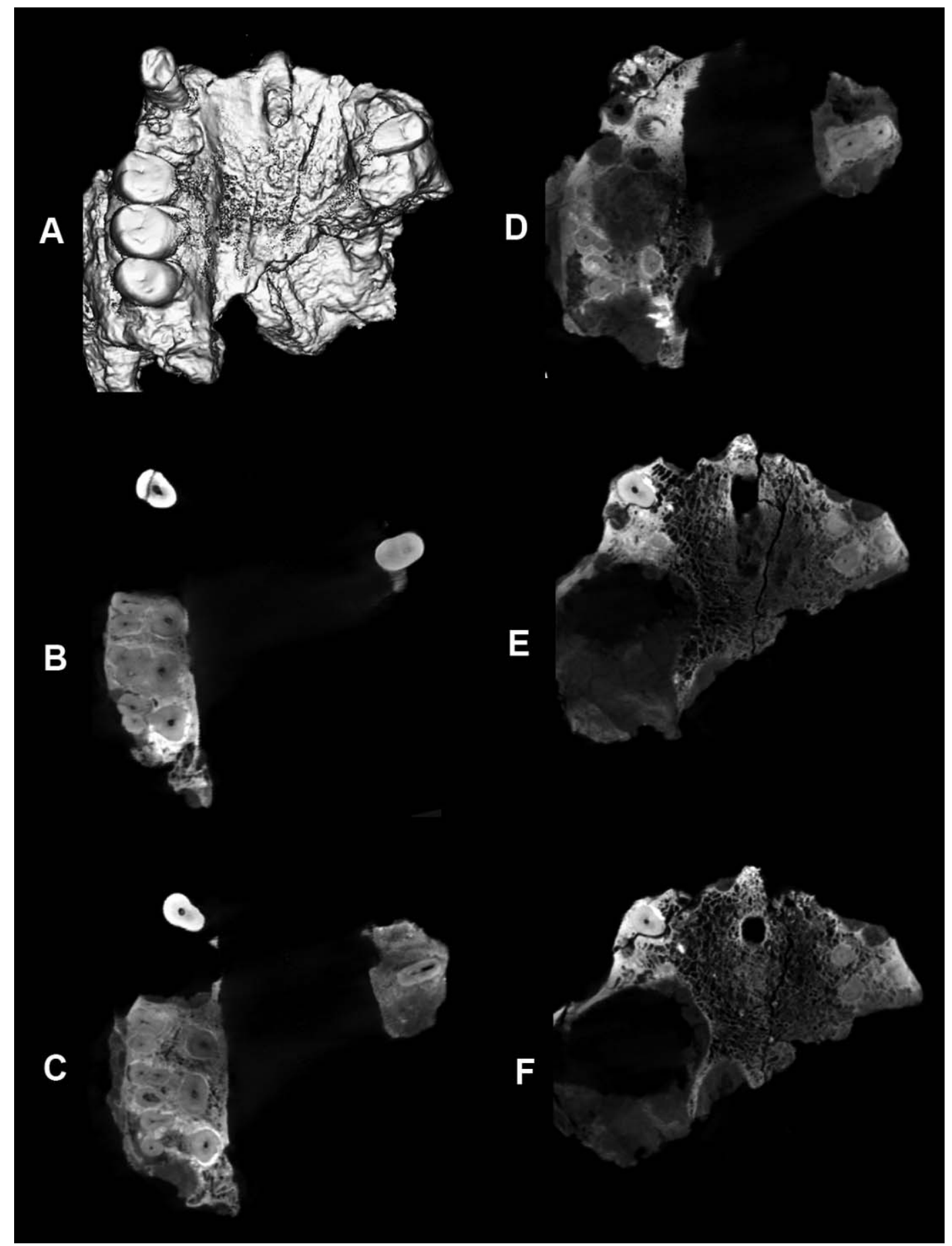

Figure 1. Three-dimensional rendering of external surface (A) and horizontal sections taken at different vertical levels (B-F) of the palate of Sangiran 17, obtained from micro-CT scanning.

ary history of Homo, at least in the Sunda region. In addition, the above discussion suggests that the masticatory environments to which Sangiran $H$. erectus and Australian Aborigines adapted were different in such a way that the former habitually experienced a stronger bite force than the latter. Thus, the observed similarity in crown size between them should be regarded as superficial, and not as indicating sim- ilar evolutionary grades.

\section{Acknowledgments}

I thank Yuji Mizoguchi, Peter Brown, and two anonymous reviewers for comments. I am grateful to Friedemann Schrenk, Johan Arif, Fachroel Aziz and Hisao Baba for 


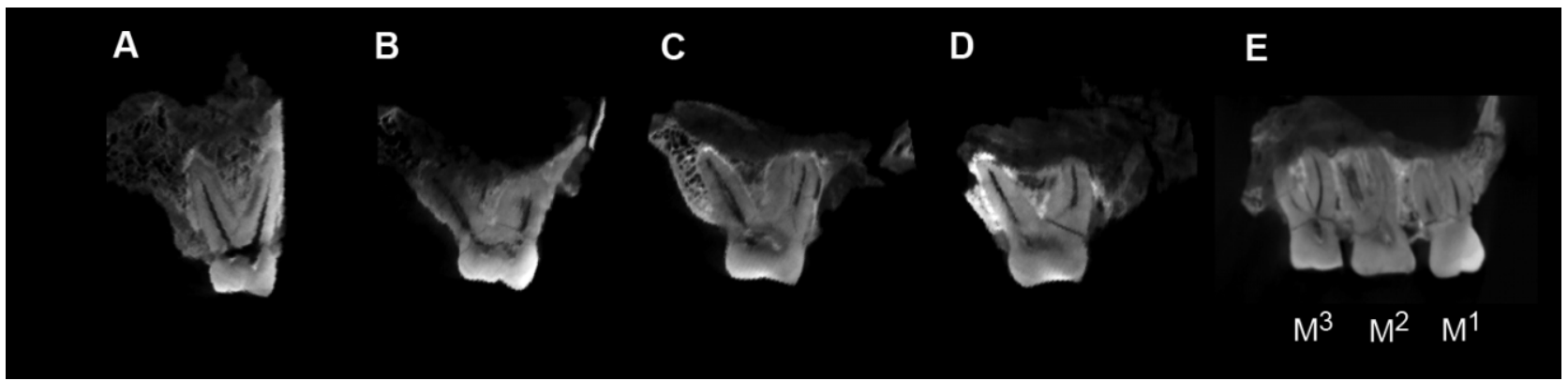

Figure 2. Micro-CT sections of the teeth of Sangiran 17. The left second premolar (A), and right first (B), second (C), and third (D) molars, sections passing through the buccal or mesiobuccal and lingual roots. Sections of the molars (E) taken through the buccal roots.

access to the specimens and support to the research. Reiko T. Kono kindly helped preparing Figure 1 . This work was supported by the Japan Society for the Promotion of Science, and the National Science Museum, Tokyo.

\section{References}

Antón S.C. (2002) Evolutionary significance of cranial variation in Asian Homo erectus. American Journal of Physical Anthropology, 118: 301-323.

Arif J., Kaifu Y., Baba H., Suparka M.E., Zaim Y., and Setoguchi T. (2002) Preliminary observation of a new cranium of Homo erectus (Tjg-1993.05) from Sangiran, Central Jawa. Anthropological Science, 110: 165-177.

Baba H., Aziz F., Kaifu Y., Suwa G., Kono R.T., and Jacob T. (2003) New Homo erectus calvarium from the Pleistocene of Java. Science, 299: 1384-1388.

Barnes D.S. (1969) Tooth morphology and other aspects of the Teso Dentition. American Journal of Physical Anthropology, 30: 183-194.

Bermúdez de Castro J.M. and Nicolás M.E. (1995) Posterior dental size reduction in hominids: the Atapuerca evidence. American Journal of Physical Anthropology, 96: 335-356.

Brace C.L., Shao X.-q., and Zhang Z.-b. (1984) Prehistoric and modern tooth size in China. In: Smith F.H. and Spencer F. (eds.), The Origins of Modern Humans: A World Survey of the Fossil Evidence. Alan R. Liss, New York, pp. 485-516.

Bräuer G. and Schultz M. (1996) The morphological affinities of the Plio-Pleistocene mandible from Dmanisi, Georgia. Journal of Human Evolution, 30: 445-481.

Brown P. (1989) Coobool Creek: a morphological and metrical analysis of the crania, mandibles and dentitions of a prehistoric Australian human population. Terra Australis 13, Department of Prehistory, Research School of Pacific Studies, Australian National University, Canberra.

Brown P. (1992a) Post-Pleistocene change in Australian Aboriginal tooth size: dental reduction or relative expansion? In: Brown T. and Molnar S. (eds.), Human Craniofacial Variation in Pacific Populations. Anthropology and Genetics Laboratory, University of Adelaide, Adelaide, pp. 33-52.

Brown P. (1992b) Recent human evolution in East Asia and Australasia. Philosophical Transactions of the Royal Society London, Series B: Biological sciences, 337: 235-242.

Brown P., Sutikna T., Morwood M.J., Soejono R.P., Jatmiko, Saptomo E.W., and Due R.A. (2004) A new small-bodied hominin from the Late Pleistocene of Flores, Indonesia. Nature, 431: $1055-1061$

Dahlberg A.A. (1960) The dentition of the first agriculturists (Jarmo, Iraq). American Journal of Physical Anthropology, 18: $243-256$

Durband A. (2004) A test of multiregional hypothesis of modern human origins using the basicranial evidence from Southeast Asia and Australia. American Journal of Physical Anthropology, Supplement 38: 90-91.

Durband A.C., Kidder J.H., and Jantz R.L. (2005) A multivariate examination of the Hexian calvaria. Anthropological Science, 113: $147-154$

Freedman L. and Lofgren M. (1981) Odontometrics of western Australian Aborigines. Archaeology in Oceania, 16: 87-93.

Gabunia L., de Lemley M.-A., Vekua A., Lordkipanidze D., and de Lumley H. (2002) Découverte d'un nouvel hominidé à Dmanissi (Transcaucasie, Géorgie). Comptes Rendus Palevol, 1: 243-253.

Grine F.E. and Franzen J.L. (1994) Fossil hominid teeth from the Sangiran Dome (Java, Indonesia). Courier Forschungsinstitut Senckenberg, 171: 75-103.

Hawks J., Oh S., Hunley K, Dobson S., Cabana G., Dayalu P., and Wolpoff M.H. (2000) An Australasian test of the recent African origin theory using the WLH-50 calvarium. Journal of Human Evolution, 39: 1-22.

Hyodo M., Watanabe N., Sunata W., Susanto E.E., and Wahyono H. (1993) Magnetostratigraphy of hominid fossil bearing formations in Sangiran and Mojokerto, Java. Anthropological Science, 101: 157-186.

Hyodo M., Nakaya H., Urabe A., Saegusa H., Xue S., Yin J., and Ji X. (2002) Paleomagnetic dates of hominid remains from Yuanmou, China, and other Asian sites. Journal of Human Evolution, 43: 27-41.

Kaifu Y., Baba H., Aziz F., Schrenk F., Jacob T., Indriati E., and Arif J. (2003) Primitive dento-gnathic morphology of Javanese Homo erectus. American Journal of Physical Anthropology, Supplement 36: 125.

Kaifu Y., Aziz F., and Baba H. (2005a) Hominid mandibular remains from Sangiran: 1952-1986 collection. American Journal of Physical Anthropology, 128: 497-519.

Kaifu Y., Baba H., Aziz F., Indriati E, Schrenk F., and Jacob T. (2005b) Taxonomic affinities and evolutionary history of the Early Pleistocene hominids of Java: Dentognathic evidence. American Journal of Physical Anthropology, 128: 709-726.

Kaifu Y., Aziz F., Baba H., Kono R.T., and Suwa G. (2005c) Subocclusal morphology of Sangiran 17. Geological Research and Development Centre, Paleontology Series (in press).

Kasai K. and Iida J. (2001) Orthodontics. Ishiyaku Shuppan, Tokyo.

Kieser J.A. (1990) Human Adult Odontometrics. Cambridge University Press, Cambridge.

Kramer A. (1991) Modern human origins in Australasia: replacement or evolution? American Journal of Physical Anthropology, 86: 455-473.

Larick R., Ciochon R.L., Zaim Y., Sudijono, Suminto, Rizal Y., Aziz F., Reagan M., and Heizler M. (2001) Early Pleistocene ${ }^{40} \mathrm{Ar} /{ }^{39} \mathrm{Ar}$ ages for Bapang Formation hominins, Central Jawa, Indonesia. Proceedings of the National Academy of Sciences 
of the United States of America, 98: 4866-4871.

Mayhall J.T. (1979) The dental morphology of the Inuit of the Canadian Central Arctic. OSSA, 6: 199-218.

Mizoguchi Y. (1988) A statistical analysis of geographical variation in dental size. A Report of the Research Supported by a Grant-in-Aid for Scientific Research from the Ministry of Education, Science and Culture, Japan (in Japanese).

Mizoguchi Y. (1993) Overall associations between dental size and foodstuff intakes in modern human populations. Homo, 44: $37-73$.

Moorrees C.F.A. (1957) The Aleut Dentition. Harvard University Press, Cambridge.

Selmer-Olsen (1949) An odontometrical study on the Norwegian Lapps. Skrift Norske Vidensk-Akademi, 3: 1-167.

Sharma J.C. (1983) Dental morphology and odontometry of the Tibetan immigrants. American Journal of Physical Anthropology, 61: 495-505.

Sharma J.C. (1985) Evolutionary significance of dental morphology and odontometry. In: Reddy V.R. (ed.), Dental Anthropology: Application and Methods. Inter-India Publications, New Delhi, pp. 251-267.

Smith P., Brown T., and Wood W.B. (1981) Tooth size and morphology in a recent Australian aboriginal populations from Broadbeach, South east Queensland. American Journal of Physical Anthropology, 55: 423-432.

Thorne A. and Wolpoff M.H. (1981) Regional continuity in Australasian Pleistocene hominid evolution. American Journal of Physical Anthropology, 55: 337-349.

Townsend G.C. and Brown T. (1979) Tooth size characteristics of Australian aborigines. In: Occasional Papers in Human Biology, No. 1. Australian Institute of Aboriginal Studies, Can- berra, pp. 17-38.

Vandermeersch B. (1981) Les Hommes Fossiles de Qafzeh (Israël). Éditionas du Centre National de la Recherche Scientifique, Paris.

Weidenreich F. (1937) The dentition of Sinanthropus pekinensis: a comparative odontography of the hominids. Paleontologia Sinica, New Series D, 1: 1-180.

Wolpoff M.H. (1980) Paleoanthropology. Alfred A. Knopf, New York.

Woo J. (1964) Mandible of the Sinanthropus-type discovered at Lantian, Shensi-Sinanthropus lantianensis. Scientia Sinica, 5: 801-811.

Wood B.A. (1991) Hominid cranial remains from Koobi Fora. Koobi Fora Research Project, Volume 4, Clarendon Press, Oxford.

Wood B.A., Abbott S.A., and Uytterschaut H. (1988) Analysis of the dental morphology of Plio-Pleistocene hominids, 4. Mandibular postcanine root morphology. Journal of Anatomy, 156: $107-139$

Wu M. (1983) Homo erectus from Hexian, Anhui found in 1981. Acta Anthropologica Sinica 2: 109-115.

Wu R. and Dong X. (1982) Preliminary study of Homo erectus remains from Hexian, Anhui. Acta Anthropologica Sinica 1: 2-13 (in Chinese).

Wu X and Poirier F.E. (1995) Human Evolution in China: A Metric Description of the Fossils and a Review of the Sites. Oxford University Press, Oxford.

Zhang Y. (1991) An examination of temporal variation in the hominid dental sample from Zhoukoudian Locality 1. Acta Anthropologica Sinica, 10: 15-22 (in Chinese). 